\title{
Produtividade de Milho e de Feijão \\ Consorciados Adubados con Diferentes \\ Formas de Lodo de Esgoto
}

\author{
Thiago Assis Rodrigues N., Regynaldo Arruda S.*, Cleidson Soares F., \\ Ivana Machado F., Luiz Arnaldo F.
}
Universidade Federal de Minas Gerais, Instituto de Ciências Agrárias, Caixa Postal 135, CEP 39.404-006 - Montes Claros, MG - Brasil.
*Correspondência:rsampaio@ufmg.br

\section{Productivity of corn and beans in intercropping systems fertilized with different sewage sludge}

Key words: Organic fertilizers, Biosolid, Urban residues recycling.

\begin{abstract}
The sewage sludge, as physical, chemical and biological conditioning of soil properties, has become important organic fertilizer. The aim of this work was to evaluate the effect of the organic fertilization with different sewage sludge on soil fertility and productivity of corn and beans in intercropping systems. The experimental design was a complete randomized blocks with three replicates. The treatments were: soil without fertilization, liming and chemical fertilization, sewage sludge, sewage sludge sanitized with nim, sewage sludge sanitized with lime, sewage sludge and ipomoea composting, sewage sludge and ipomoea composting with rock phosphate, sewage sludge with rock phosphate incorporated at soil, sewage sludge sanitized with nim and rock phosphate incorporated at soil, sewage sludge sanitized with lime and rock phosphate incorporated at soil, sewage sludge and ipomoea composting with rock phosphate incorporated at soil. The data had been submitted to the analysis of variance and test of Scott-Knott at 5\% of probability. The application of sewage sludge with lime increased the alkalinity of the soil and, also, the nutrients available for the plants. However, the changes observed in the chemical characteristics of the soil with the application of the biosolid had not influenced the productivity of the cultures of corn and beans in intercropping system.
\end{abstract}




\section{RESUMO}

O lodo de esgoto, em razão da sua atuação como condicionador das propriedades físicas, químicas e biológicas do solo, pode se constituir em um importante adubo orgânico. O presente trabalho buscou avaliar o efeito da adubação com diferentes formas de lodo de esgoto sobre a fertilidade do solo e produtividade de grãos de milho e de feijão consorciados. Os tratamentos, no delineamento em blocos casualizados, com 3 repetições, corresponderam a: Solo sem adubação, Calagem e adubação química, Lodo não higienizado, Lodo higienizado com nim, Lodo higienizado com cal, Composto de lodo e ipomoea, Composto de lodo e ipomoea com fosfato, Lodo não higienizado e fosfato no solo, Lodo higienizado com nim e fosfato no solo, Lodo higienizado com cal e fosfato no solo, Composto de lodo e ipomoea e fosfato no solo. Os dados obtidos foram submetidos à análise de variância e teste de Scott-Knott a 5\% de probabilidade. A aplicação de lodo de esgoto tratado com cal aumentou a alcalinidade do solo e, também, a disponibilidade de nutrientes para as plantas. Entretanto, as mudanças observadas nas características químicas do solo com a aplicação deste insumo não influenciaram a produtividade das culturas de milho e de feijão consorciados. Palavras-chave: Adubo orgânico, Biossólido, Reciclagem de resíduos urbanos.

\section{INTRODUÇÃO}

A crescente população dos centros urbanos é importante produtora de diversos resíduos, os quais, muitas vezes, são acumulados no ambiente sem o adequado tratamento, ou utilização, que possibilite sua reciclagem. Dentre esses resíduos, pode-se destacar o lodo de esgoto, ou biossólido, resultante do tratamento das águas servidas, que apresenta potencialidade para utilização agrícola. Este resíduo contém considerável percentual de matéria orgânica e de elementos essenciais para as plantas, podendo substituir, ainda que parcialmente, os fertilizantes minerais, podendo desempenhar importante papel na produção agrícola e na manutenção da fertilidade do solo (Nascimento et al., 2004).

As principais formas de transformação ou destinação do lodo de esgoto são o aterramento, a incineração e a aplicação no solo. O aterro é um método que utiliza princípios de engenharia para o confinamento dos resíduos a menor área $\mathrm{e}$ volume possíveis, cobrindo-os com uma camada de terra sempre que necessário. A incineração é um método de tratamento que se utiliza da decomposição térmica via oxidação, com o objetivo de tornar um resíduo menos volumoso, menos tóxico ou atóxico, ou ainda eliminá-lo, em alguns casos. Do ponto de vista sustentável, a eliminação do lodo através de incineração ou pela disposição em aterros sanitários somente é empregada quando sua valorização é impossível, devido principalmente à presença de contaminantes no lodo.

Desta forma, a aplicação do lodo de esgoto no solo apresenta-se como uma tendência mundial (Lopes et al., 2005). Esta técnica consiste na disposição do lodo uniformemente sobre o terreno de modo a promover a melhoria das condições do solo ou do desenvolvimento da cobertura vegetal implantada. No Brasil, existem experiências como a de Curitiba, onde foi criado no início desta década o programa para a reciclagem agrícola do lodo de esgoto. Alternativas com estas têm apresentado bons resultados, conforme relatam Silva et al. (2002), podendo ser utilizado por meio da reciclagem, na agricultura, silvicultura, floricultura, paisagismo ou recuperação de áreas degradadas submetidas a processo de revegetação para recuperação. A reciclagem via utilização agronômica é a forma que apresenta maior potencial em razão do seu uso como fertilizante e condicionador do solo, além dos maiores benefícios ambientais. 
O lodo de esgoto, dependendo do tipo de tratamento das águas residuárias e da época de sua produção, caracteriza-se por apresentar quantidades elevadas de matéria orgânica. Neste aspecto, o lodo de esgoto desempenha uma função extremamente importante na dinâmica dos solos, influindo em suas características químicas, físico-químicas, biológicas e físicas (Barbosa et al., 2004).

Dentre os efeitos do lodo de esgoto sobre as propriedades físicas do solo, condicionadas principalmente pela presença de matéria orgânica, destacam-se a melhoria no estado de agregação das partículas do solo, com conseqüente diminuição da densidade e aumento na aeração e retenção de água (Melo et al, 2004). Quanto aos aspectos químicos, a aplicação de lodo ao solo tem propiciado elevação dos teores de fósforo, de carbono orgânico, da fração humina da matéria orgânica, do $\mathrm{pH}$, da condutividade elétrica e da capacidade de troca de cátions (Nascimento et al., 2004).

Segundo Andreolli (1999), a aplicação no solo destaca-se pela viabilização da reciclagem de nutrientes, promoção de melhorias físicas, especialmente na estruturação do solo e por ser uma solução de longo alcance para destinação do lodo. As maiores limitações para o emprego deste método são os riscos de contaminação do solo com metais pesados e agentes patogênicos (Lopes et al., 2005). Também, deve se destacar a necessidade de disponibilidade de grandes áreas, a possibilidade de lixiviação de nitrogênio e fósforo, contaminando o lençol freático e as águas superficiais, e a possibilidade da ocorrência de problemas como atração de insetos vetores, pequenos roedores e liberação de odores quando não houver estabilização suficiente do lodo. Todavia, a composição e o nível dos contaminates depende da origem dos rejeitos, tais como esgotos domésticos, industriais e hospitalares (Rocha et al., 2003).
De acordo com Nascimento et al. (2004) são evidentes os resultados positivos apresentados por culturas como soja, trigo, milho, feijão e girassol, com a aplicação de lodo de esgoto. Segundo Andreolli et al. (1999) foram observados aumentos de produtividade com o uso deste insumo no sistema de cultivo de bracatinga consorciado com o milho e feijão, sendo o retorno financeiro com base no investimento em adubo, quatro vezes maior com o uso do lodo de esgoto quando comparado a adubação mineral. Lourenço et al. (1996) também verificou efeito residual para cultivos subseqüentes, quando o lodo de esgoto foi empregado em doses elevadas.

O presente trabalho teve como objetivo principal avaliar o efeito da adubação com diferentes formas de lodo de esgoto associado a aplicação de fosfato natural sobre a fertilidade do solo e produtividade de grãos de milho e de feijão consorciados.

\section{MATERIALEMÉTODOS}

O experimento foi realizado na área experimental do Campus da UFMG em Montes Claros-MG, em CAMBISSOLO HÁPLICO, com as características químicas e físicas apresentadas no (Quadro 1). Foram utilizadas como plantas indicadoras, em dois cultivos consecutivos, o milho crioulo CAA (Zea mays L.) e o feijão trepador (Vigna unguiculata (L.) Walp) consorciados. 


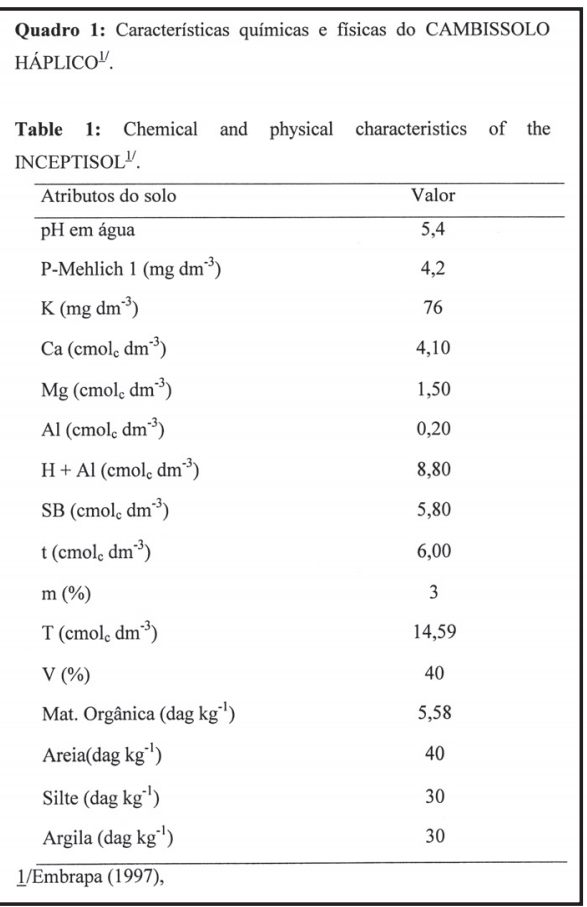

O lodo de esgoto desidratado foi coletado na Estação de Tratamento de Esgoto - ETE no município de Juramento MG, sendo esta operada pela Copasa-MG, e a macrófita Ipomoea carnea ssp. fistulosa adquirida do reservatório do Sistema Verde Grande, onde se constitui em uma importante praga que onera os custos de manutenção do sistema de abastecimento de água da cidade de Montes Claros.

Logo após a aquisição dos materiais (lodo de esgoto e ipomoea) foram feitas análises laboratoriais seguindo metodologias preconizadas por Tedesco (1995): Matéria Orgânica, pH, Umidade, Carbono e Nitrogênio, tanto para o lodo quanto para a Ipomoea (Quadro 2). Sendo que o Carbono e o Nitrogênio foram utilizados para calcular a relação $\mathrm{C} / \mathrm{N}$ para a formação da compostagem.

Quadro 2: Características químicas e físicas das amostras de lodo de esgoto não higienizado e de ipomoea ${ }^{1 /}$.

Table 2: Chemical and physical characteristics of the samples of sewage sludge not sanitized and ipomoea ${ }^{\underline{1}}$.

\begin{tabular}{lccccc}
\hline \multicolumn{1}{c}{ Materiais } & $\mathrm{pH}-\mathrm{H}_{2} \mathrm{O}$ & Mat. Orgânica & $\mathrm{N}$ & $\mathrm{C}$ & Umidade $65^{\circ} \mathrm{C}$ \\
\hline \multirow{2}{*}{ Lodo de esgoto } & 4,8 & 16,20 & 2,4 & 9,42 & 6,0 \\
Ipomoea & 5,3 & 81,62 & 0,6 & 47,09 & 47,00 \\
\hline
\end{tabular}

1/Tedesco (1995). 
A compostagem do lodo foi efetuada juntamente com a Ipomoea carnea ssp. fistulosa triturada com o uso de um desintegrador elétrico, tendo a meda uma altura de aproximadamente 1,5 m. Diariamente monitorou-se a temperatura e a umidade do material. Sempre que necessário efetuouse o revolvimento manual das pilhas, utilizando-se pás e enxadas. A temperatura foi medida através de barras de ferro introduzida na pilha de compostagem em três pontos específicos do topo, do meio e da base. A umidade foi determinada pela secagem em estufa a $105^{\circ} \mathrm{C}$ até peso constante. Ao final do processo de degradação, o material foi estocado por mais 30 dias para a maturação do composto.

A macrófita Ipomoea carnea ssp. fistulosa misturado ao lodo de esgoto apresentou bons resultados na produção de composto orgânico, constituindo-se em uma importante fonte de adubo para uso agrícola, podendo ser explorado pela Copasa.

O experimento contou com 11 tratamentos, distribuídos no delineamento em blocos casualizados, com três repetições, conforme mostrado a seguir:

* $\mathrm{T}_{1}$ - Testemunha (solo sem adubação);

* $\mathrm{T}_{2}$ - Calagem e adubação química convencional;

* $\mathrm{T}_{3}$ - Aplicação de 16,7 t/ha de lodo de esgoto seco não higienizado;

* $\mathrm{T}_{4}$ - Aplicação de 13,8 t/ha de lodo de esgoto seco higienizado com extrato de Nim (Azadirachta indica);

* $\mathrm{T}_{5}$ - Aplicação de 33,2 t/ha de lodo de esgoto seco tratado com cal virgem;

* $\mathrm{T}_{6}$ - Aplicação de 28,1 t/ha composto orgânico feito com lodo de esgoto e Ipomoea;

* $\mathrm{T}_{7}$ - Aplicação de 30,6 t/ha composto orgânico feito com lodo de esgoto e Ipomoea, com adição no início da compostagem de $2 \%$ de fosfato natural reativo;

* $\mathrm{T}_{8}$ - Aplicação de 14,1 t/ha de lodo de esgoto seco não higienizado + Aplicação no campo de $200 \mathrm{~kg} / \mathrm{ha}$ de fosfato natural reativo;

* $\mathrm{T}_{9}-$ Aplicação de 13,1 t/ha de lodo de esgoto seco higienizado com extrato de $\mathrm{Nim}$ + Aplicação no campo de $200 \mathrm{~kg} / \mathrm{ha}$ de fosfato natural reativo;

* $\mathrm{T}_{10}$ - Aplicação de 31,8 t/ha de lodo de esgoto seco tratado com cal virgem + Aplicação no campo de $200 \mathrm{~kg} / \mathrm{ha}$ de fosfato natural reativo;

* $\mathrm{T}_{11}$ - Aplicação de 24,8 t/ha composto orgânico feito com lodo de esgoto e Ipomoea + Aplicação no campo de $200 \mathrm{~kg} /$ ha de fosfato natural reativo.

As variações nas dosagens do lodo foram estabelecidas conforme sua umidade e na exigência de nitrogênio pela cultura do milho (115 Kg/ha de N), baseando-se na disponibilidade deste elemento presente no lodo ou no composto de lodo e ipomoea. Também, considerou uma taxa de mineralização do material da ordem de $50 \%$ por ano.

Os tratamentos higienizados com Nim receberam meio litro de extrato aquoso de folhas de Nim (Azadirachta indica) para cada litro de lodo de esgoto seco.

Os tratamentos higienizados com cal foram tratados na proporção de $50 \%$ do peso seco de lodo $+50 \%$ do peso seco de cal virgem, misturados a $70 \%$ de umidade do lodo.

No tratamento com calagem e adubação química foram aplicados $3,65 \mathrm{t} / \mathrm{ha}$ de calcário dolomítico, para elevação da saturação de bases para $70 \%$, e $575,66,7$ e $500 \mathrm{~kg} / \mathrm{ha}$ de sulfato de amônio, cloreto de potássio e superfosfato simples, respectivamente, com base na análise do solo e na recomendação de adubação para a cultura do milho,

As características químicas das diferentes formas de lodo de esgoto utilizadas no experimento são apresentadas no Quadro 3 . Os teores totais dos nutrientes foram determinados no extrato ácido (ácido nítrico e ácido perclórico), conforme metodologia preconizada por Tedesco (1995). 
Quadro 3: $\mathrm{pH}$ e teores totais de nutrientes nos tratamentos contendo lodo de esgoto.

Table 3: $\mathrm{pH}$ and nutrients concentrations in the treatments contend sewage sludge.

\begin{tabular}{|c|c|c|c|c|c|c|c|c|c|}
\hline \multirow[t]{2}{*}{ Tratamentos } & $\mathrm{pH}-\mathrm{H}_{2} \mathrm{O}$ & $\mathrm{N}$ & $\mathrm{P}$ & $\mathrm{K}$ & $\mathrm{Ca}$ & $\mathrm{Mg}$ & $S$ & C.O. & $\mathrm{C} / \mathrm{N}$ \\
\hline & \multicolumn{7}{|c|}{ - - } & \multicolumn{2}{|l|}{$\%$} \\
\hline Lodo não higienizado & 4,40 & 10,4 & 2,9 & 5,8 & 7,0 & 3,2 & 11,5 & 6,55 & 6,29 \\
\hline Lodo + Nim & 4,75 & 7,8 & 3,0 & 5,6 & 6,5 & 3,0 & 9,2 & 7,02 & 9,00 \\
\hline Lodo + Cal & 12,02 & 14,0 & 1,7 & 4,0 & 146,6 & 2,6 & 6,3 & 3,74 & 2,67 \\
\hline Compostagem & 5,06 & 10,6 & 1,3 & 4,4 & 14,6 & 1,6 & 6,5 & 12,6 & 11,88 \\
\hline Compostagem $+\mathrm{FN}^{1 /}$ & 4,56 & 10,9 & 3,7 & 5,8 & 18,5 & 2,2 & 6,1 & 12,00 & 11,00 \\
\hline
\end{tabular}

O primeiro cultivo das plantas foi realizado no período de abril a setembro de 2004 e o segundo cultivo no período de janeiro a junho de 2005. Foram semeadas cinco sementes de milho e duas de feijão por cova, sendo feito desbaste após quinze dias deixando apenas uma planta de milho e uma de feijão. O espaçamento utilizado para as culturas foi de $0,5 \mathrm{~m}$ entre plantas e de $1,0 \mathrm{~m}$ entre fileiras, em parcelas de $14 \mathrm{~m}^{2}$.Cada parcela foi cultivada com 28 plantas de milho e 28 de feijão em consórcio na mesma cova, sendo consideradas bordaduras as fileiras externas.

Ao longo dos cultivos foram realizados tratos culturais com a aplicação de inseticida (STR0N, organofosforado sistêmico da agripec na quantidade de $25 \mathrm{~mL} / 500 \mathrm{~m}^{2}$ ), para o controle de Diabrotica speciosa, Cerotoma arcuata e Spodoptera frugiperda, tendo sido realizadas duas aplicações. Utilizou-se para irrigação um sistema fixo de aspersão constituído de duas linhas secundárias com um número total de seis aspersores. Foi adotado tanque Classe A para o manejo da irrigação. Foram feitas na área capinas manuais sistemáticas.

As colheitas do feijão e do milho foram realizadas, respectivamente, aos 90 e 160 dias após o plantio, considerando-se a porcentagem de umidade para a colheita de grãos, sendo esta posteriormente ajustada para $13 \%$.

Em relação ao feijão e milho foram analisadas as seguintes variáveis: $\mathrm{N}^{\mathrm{o}}$ de Vagens/Planta de feijão, $\mathrm{N}^{\circ}$ Grãos/Vagem de feijão, $N^{0}$ de Grãos de feijão/Planta, Massa de 100 grãos de feijão, Produtividade do feijão, $\mathrm{N}^{\circ}$ de Espigas/Planta de milho, $\mathrm{N}^{\circ}$ Grãos/Espigas de milho, Massa de 100 grãos de milho e Produtividade do milho.

Em relação ao solo, foram determinados em amostras coletadas na profundidade de 0 a $20 \mathrm{~cm}$ : o $\mathrm{pH}$ e os teores de $\mathrm{P}, \mathrm{K}, \mathrm{Ca}, \mathrm{Mg}$, $\mathrm{Al}, \mathrm{H}+\mathrm{Al}$ e Matéria Orgânica, de acordo com as metodologias preconizadas por Tedesco (1995).

Os dados obtidos foram submetidos à análise de variância e as médias comparadas até $5 \%$ de probabilidade pelo teste de Scott-Knott.

\section{RESULTADOS E DISCUSSÃO}

Os valores de $\mathrm{pH}$ e $\mathrm{Ca}$ do solo foram maiores nos tratamentos em que o lodo de esgoto foi tratado com cal (Quadro 4). Tal fato pode ser atribuído ao $\mathrm{Ca}$ existente na cal e a capacidade de hidrólise desta última, razão pela qual o $\mathrm{pH}$ atingiu valores muito elevados para estes tratamentos. 
Quadro 4: Características químicas do solo cultivado com milho e feijão em função dos tratamentos aplicados ${ }^{1 /}$.

Table 4: Chemical characteristics of soil cultivated with corn and beans in function of the applied treatments ${ }^{\underline{1}}$.

\begin{tabular}{crrrrrrr}
\hline Tratamento $\mathrm{pH}-\mathrm{H}_{2} \mathrm{O}$ & $\mathrm{P}$ & $\mathrm{K}$ & $\mathrm{Ca}$ & $\mathrm{Mg}$ & $\mathrm{H}+\mathrm{Al}$ & Mat. Orgânica \\
\hline & & $------\mathrm{mg} \mathrm{dm}^{-3}-----$ & $--------\mathrm{cmol}_{\mathrm{c}} \mathrm{dm}^{-3}--------$ & --- & dag kg \\
& & & & $-1---$ \\
$\mathrm{T}_{1}$ & $7,13 \mathrm{~b}$ & $4,17 \mathrm{~d}$ & $144,00 \mathrm{~b}$ & $5,93 \mathrm{~b}$ & $1,90 \mathrm{a}$ & $1,59 \mathrm{~b}$ & $2,14 \mathrm{a}$ \\
$\mathrm{T}_{2}$ & $7,20 \mathrm{~b}$ & $100,67 \mathrm{a}$ & $219,00 \mathrm{a}$ & $8,10 \mathrm{~b}$ & $2,70 \mathrm{a}$ & $1,06 \mathrm{~b}$ & $2,06 \mathrm{a}$ \\
$\mathrm{T}_{3}$ & $6,63 \mathrm{c}$ & $18,13 \mathrm{~d}$ & $165,33 \mathrm{a}$ & $7,20 \mathrm{~b}$ & $2,37 \mathrm{a}$ & $1,79 \mathrm{~b}$ & $2,68 \mathrm{a}$ \\
$\mathrm{T}_{4}$ & $5,33 \mathrm{c}$ & $12,53 \mathrm{~d}$ & $112,00 \mathrm{~b}$ & $5,57 \mathrm{~b}$ & $1,57 \mathrm{a}$ & $2,99 \mathrm{a}$ & $2,51 \mathrm{a}$ \\
$\mathrm{T}_{5}$ & $8,33 \mathrm{a}$ & $28,20 \mathrm{~d}$ & $103,33 \mathrm{~b}$ & $10,37 \mathrm{a}$ & $2,27 \mathrm{a}$ & $0,57 \mathrm{~b}$ & $2,66 \mathrm{a}$ \\
$\mathrm{T}_{6}$ & $5,97 \mathrm{c}$ & $17,93 \mathrm{~d}$ & $106,33 \mathrm{~b}$ & $6,10 \mathrm{~b}$ & $1,70 \mathrm{a}$ & $2,36 \mathrm{a}$ & $3,52 \mathrm{a}$ \\
$\mathrm{T}_{7}$ & $6,57 \mathrm{c}$ & $71,10 \mathrm{~b}$ & $191,00 \mathrm{a}$ & $6,90 \mathrm{~b}$ & $1,83 \mathrm{a}$ & $1,60 \mathrm{~b}$ & $3,18 \mathrm{a}$ \\
$\mathrm{T}_{8}$ & $5,87 \mathrm{c}$ & $89,23 \mathrm{a}$ & $88,33 \mathrm{~b}$ & $6,63 \mathrm{~b}$ & $1,60 \mathrm{a}$ & $2,66 \mathrm{a}$ & $2,61 \mathrm{a}$ \\
$\mathrm{T}_{9}$ & $6,23 \mathrm{c}$ & $52,23 \mathrm{c}$ & $189,67 \mathrm{a}$ & $6,10 \mathrm{~b}$ & $1,97 \mathrm{a}$ & $2,36 \mathrm{a}$ & $2,42 \mathrm{a}$ \\
$\mathrm{T}_{10}$ & $8,40 \mathrm{a}$ & $27,63 \mathrm{~d}$ & $85,33 \mathrm{~b}$ & $10,47 \mathrm{a}$ & $1,90 \mathrm{a}$ & $0,55 \mathrm{~b}$ & $2,28 \mathrm{a}$ \\
$\mathrm{T}_{11}$ & $6,73 \mathrm{c}$ & $43,87 \mathrm{c}$ & $143,00 \mathrm{~b}$ & $6,97 \mathrm{~b}$ & $1,67 \mathrm{a}$ & $1,55 \mathrm{~b}$ & $2,91 \mathrm{a}$
\end{tabular}

1/Medologia da Embrapa (1997).

$\mathbf{T}_{\mathbf{1}}$ - Solo sem adubação, $\mathbf{T}_{\mathbf{2}}$ - Calagem e adubação química, $\mathbf{T}_{\mathbf{3}}$ - Lodo não higienizado, $\mathbf{T}_{\mathbf{4}}$ - Lodo higienizado com nim, $\mathbf{T}_{5}$ - Lodo higienizado com cal, $\mathbf{T}_{6}$ - Composto de lodo e ipomoea, $\mathbf{T}_{7}$ - Composto de lodo e ipomoea com fosfato, $\mathbf{T}_{\mathbf{8}}$ - Lodo não higienizado e fosfato no solo, $\mathbf{T}_{\mathbf{9}}$ - Lodo higienizado com nim e fosfato no solo, $\mathbf{T}_{\mathbf{1 0}}$ - Lodo higienizado com cal e fosfato no solo, $\mathbf{T}_{\mathbf{1 1}}$ - Composto de lodo e ipomoea e fosfato no solo.

Médias seguidas da mesma letra na vertical não diferem estatisticamente entre si a $5 \%$ de probabilidade pelo teste de Scott Knott.

De acordo com Andreoli et al. (1999) a adição de cal ao lodo de esgoto é uma prática comum que visa à eliminação de patógenos e estabilização do resíduo para uso agrícola. $\mathrm{O}$ aumento do $\mathrm{pH}$ do solo com o uso do lodo tratado com cal foi relatado por Melo et al. (2002), os quais consideram que a intensidade das mudanças no $\mathrm{pH}$ depende principalmente da textura e da capacidade tampão do solo. Os menores valores de $\mathrm{pH}$ do solo observados nos tratamentos com aplicação de lodo de esgoto não tratado com cal podem ser atribuídos ao processo de nitrificação, onde o amônio é oxidado a nitrito e nitrato, com a produção líquida de dois íons de $\mathrm{H}^{+}$e conseqüente redução do pH (Bettiol e Fernandes, 2004). Também, Simonete et al. (2003) afirmam que a acidificação pode estar associada, além das reações de nitrificação do $\mathrm{N}$ amoniacal, a provável oxidação de sulfitos e à produção de ácidos orgânicos durante a degradação dos resíduos por microrganismos. Por outro lado, constatou-se neste experimento, após 
o cultivo, aumento do $\mathrm{pH}$ e do teor de $\mathrm{Ca}$ do solo, inclusive da testemunha (Quadro 4), quando comparados aos valores iniciais do solo (Quadro 1), possivelmente em razão da água utilizada na irrigação ser de origem calcária (pH 7,2 e alcalinidade $262 \mathrm{mg} \mathrm{L}^{-1}$ $\mathrm{CaCO}_{3}$ ).

Em relação ao teor de $\mathrm{P}$ disponível, observa-se no (Quadro 4) que em geral os maiores valores deste elemento ocorreram nos tratamentos que receberam adubação química e fosfato natural aplicado ao solo. Também, ficou evidente o aumento do teor deste elemento com a aplicação de lodo de esgoto comparado ao teor inicial do solo (Quadro 1). Segundo Melo et al. (2002) ainda existem dúvidas quanto ao potencial do lodo em aumentar a disponibilidade de $\mathrm{P}$ no solo, entretanto, Hue (1995) afirma que o lodo pode atuar diminuindo a adsorção de $\mathrm{P}$ no solo, em razão do elevado teor de matéria orgânica que poderá fornecer íons orgânicos que competem com o fosfato pelos sítios de adsorção.

$\mathrm{O} \mathrm{K}$, em razão da baixa concentração no lodo, tem sido o elemento de maior necessidade de suplementação com fertilizantes minerais quando da sua utilização para adubação (Melo et al., 2002). Tal fato ocorre em razão do K manter-se em solução e ser eliminado com as águas residuárias, permanecendo pouco deste elemento no lodo de esgoto (Simonete et al., 2003). No presente trabalho, constatou-se aumento dos teores de K em relação ao teor inicial do solo (Quadros 1 e 4), inclusive da testemunha, o que sugere alguma contribuição da água de irrigação. Dentre os tratamentos, a maior contribuição para o aumento do teor de $\mathrm{K}$ no solo foi principalmente da adubação química (Quadro 4).

Os teores de $\mathrm{Mg}$ após o cultivo de milho e feijão (Quadro 4) aumentaram em relação aos teores iniciais do solo (Quadro 1). O aumento do teor de $\mathrm{Mg}$ no solo, com a aplicação do lodo de esgoto, também foi observado por Simonete et al. (2003). Não houve, entretanto, diferenças estatísticas entre tratamentos em relação a este elemento.

O teor de Al no solo, antes da incorporação de adubo químico e do lodo de esgoto, apresentou valor muito baixo (Quadro 1), destacando o efeito da calagem em cultivos anteriores na precipitação do Al trocável, fato também constatado pela concentração elevada de Ca e Mg. Após o plantio de milho e de feijão o teor de alumínio foi zero.

A acidez potencial $(\mathrm{H}+\mathrm{Al})$ do solo antes do cultivo apresentou valor alto (Quadro 1), diminuindo para valores baixos após o cultivo, com destaque principalmente para os tratamentos que receberam adição de cal ao lodo de esgoto (Quadro 4). Tal fato evidencia a influência da qualidade da água usada na irrigação, uma vez que, segundo Trannin et al. (2005), a aplicação de biossólido ao solo promove a diminuição do $\mathrm{pH}$, aumento da acidez potencial e do Al trocável e da saturação por Al. De acordo com estes autores, a mineralização do $\mathrm{N}$ orgânico e subseqüente nitrificação contribuem para a acidificação do solo. Também, a biodegradação da matéria orgânica decomponível pode causar acidificação transiente no solo em razão da produção de ácidos orgânicos.

Os teores de matéria orgânica do solo ao final do cultivo (Quadro 4) diminuiram comparados ao teor inicial do solo (Quadro 1). Comportamento contrário foi observado por Nascimento et al. (2004), que constataram expressivos aumentos nos teores de matéria orgânica com a aplicação de lodo de esgoto em solos do semi-árido, apresentando aumentos de $53 \%$, em Espodossolo, e de $62 \%$, em Argissolo, sendo este aporte especialmente importante para os solos dessa região que, naturalmente, apresentam teores baixos de matéria orgânica. Resultados similares a este também foram observados por Simonete et al. (2003) e Melo et al. (2004). No entanto, Melo et al. (1994) e Oliveira et al. (2002) relatam que a manutenção de altos teores de matéria orgânica pela adição de lodo dependerá de 
aplicações sucessivas do resíduo, visto que, os efeitos sobre os teores de carbono orgânico do solo podem ser temporários em decorrência da rápida decomposição da matéria orgânica em condições tropicais. Conforme se observa no (Quadro 4), não houve diferença estatística no teor de matéria orgânica para os diferentes tratamentos. O teor de matéria orgânica verificado na testemunha resulta dos restos de palhadas de milho e feijão acumulados e incorporados ao solo ao longo do plantio.

A soma de bases, a saturação por bases, a CTC efetiva e a CTC total do solo aumentaram após o plantio (Quadro 5) em relação aos valores iniciais do solo (Quadro 1). Em geral, os maiores valores observados para estas variáveis foram para os tratamentos com adubação química e calagem e lodo de esgoto tratado com cal, evidenciando neste último a contribuição do Ca para o aumento da fertilidade do solo. Silva et al. (1998) constatou que o lodo de esgoto aplicado ao solo neutralizou parte da acidez potencial, provocando aumento do $\mathrm{pH}$ do solo, e proporcionou aumento da CTC, da soma de bases e da percentagem de saturação por bases do solo.

Quadro 5: Soma de bases trocáveis (SB), CTC efetiva (t), CTC total (T) e saturação por bases (V) em função dos tratamentos aplicados.

Table 5: Sum of exchangeable basis (SB), effective cation exchange capacity (t), total cation exchange capacity (T) and basis saturation (V) in function of the applied treatments.

\begin{tabular}{ccccc}
\hline Tratamento & $\mathrm{SB}$ & $\mathrm{t}$ & $\mathrm{T}$ & $\mathrm{V}$ \\
\hline & $8,20 \mathrm{~b}$ & $8,20 \mathrm{~b}$ & $9,78 \mathrm{~b}$ & $83,51 \mathrm{~b}$ \\
$\mathrm{~T}_{1}$ & $11,36 \mathrm{a}$ & $11,36 \mathrm{a}$ & $12,42 \mathrm{a}$ & $91,37 \mathrm{a}$ \\
$\mathrm{T}_{2}$ & $9,99 \mathrm{~b}$ & $9,99 \mathrm{~b}$ & $11,78 \mathrm{a}$ & $83,95 \mathrm{~b}$ \\
$\mathrm{~T}_{3}$ & $7,42 \mathrm{~b}$ & $7,49 \mathrm{~b}$ & $10,40 \mathrm{~b}$ & $71,28 \mathrm{~b}$ \\
$\mathrm{~T}_{4}$ & $12,89 \mathrm{a}$ & $12,90 \mathrm{a}$ & $13,46 \mathrm{a}$ & $95,76 \mathrm{a}$ \\
$\mathrm{T}_{5}$ & $8,07 \mathrm{~b}$ & $8,07 \mathrm{~b}$ & $10,43 \mathrm{~b}$ & $77,31 \mathrm{~b}$ \\
$\mathrm{~T}_{6}$ & $9,22 \mathrm{~b}$ & $9,22 \mathrm{~b}$ & $10,82 \mathrm{~b}$ & $85,10 \mathrm{~b}$ \\
$\mathrm{~T}_{7}$ & $8,46 \mathrm{~b}$ & $8,45 \mathrm{~b}$ & $11,11 \mathrm{~b}$ & $76,43 \mathrm{~b}$ \\
$\mathrm{~T}_{8}$ & $8,55 \mathrm{~b}$ & $8,55 \mathrm{~b}$ & $10,90 \mathrm{~b}$ & $78,54 \mathrm{~b}$ \\
$\mathrm{~T}_{9}$ & $12,58 \mathrm{a}$ & $12,58 \mathrm{a}$ & $13,76 \mathrm{a}$ & $95,80 \mathrm{a}$ \\
$\mathrm{T}_{10}$ & $9,00 \mathrm{~b}$ & $9,00 \mathrm{~b}$ & $10,55 \mathrm{~b}$ & $85,27 \mathrm{~b}$ \\
$\mathrm{~T}_{11}$ & &
\end{tabular}

Médias seguidas da mesma letra na vertical não diferem estatisticamente entre si a 5\% de probabilidade pelo teste de Scott Knott. 
Conforme observado no (Quadro 6), considerando as médias de dois cultivos consecutivos, não foram constatadas diferenças em relação ao número de vagens por planta de feijão, número de grãos por vagem de feijão, produtividade do feijão, número de espigas por planta de milho, número de grãos por espiga de milho, massa de 100 grãos e produtividade do milho. A não diferença estatística para produtividade do milho e do feijão pode ser atribuída a um nível razoável de fertilidade já existente no solo, em razão de cultivos anteriores, e a menor exigência das variedades utilizadas, que consistem em variedades crioulas cultivadas por pequenos agricultores, as quais praticamente não aportam insumos para os seus cultivos. Neste aspecto, as mudanças observadas nas características químicas do solo não foram suficientes para influenciar a produtividade das culturas. Entretanto, é importante destacar que Nascimento et al. (2004) observaram efeito positivo da aplicação de doses crescentes de lodo nas culturas de milho e feijão em espodossolo e argissolo. Também, Silva et al. (2002) constataram que uma dose de $6 \mathrm{t} / \mathrm{ha}$ de lodo seco teve efeito residual sobre a produção de milho até o terceiro ano após sua aplicação, o que indica a potencialidade fertilizante deste insumo.

Quadro 6: Número de vagens por planta de feijão (NV), número de grãos por vagem de feijão (GF), número de grãos de feijão por planta (GP), massa de 100 grãos de feijão (MGF), produtividade de feijão (PF), número de espigas de milho por planta (NE), número de grãos por espiga de milho (NG), massa de 100 grãos de milho (MGM) e produtividade do milho (PM) em função dos tratamentos aplicados.

Table 6: Number of pod by beans plant (NV), number of grains by beans pod (GF), number of beans grains by plant (GP), 100 grains mass of beans (MGF), beans productivity (PF), number of maize ears for plant (NE), number of grains by maize ears (NG), 100 grains mass of maize (MGM) and productivity of the maize (PM) in function of the applied treatments.

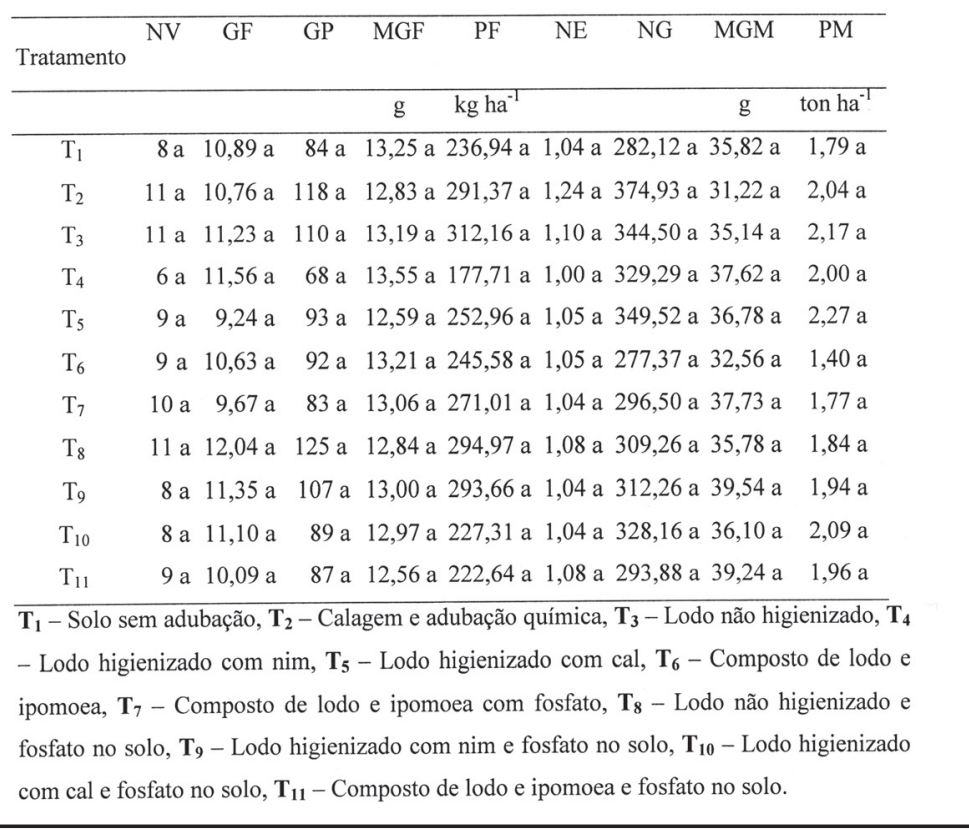


As produtividades médias do milho e do feijão foram da ordem de 1,93 t/ha e 256 $\mathrm{kg} / \mathrm{ha}$, respectivamente, sendo compatíveis com as médias de produtividades de variedades locais (Oliveira e Araújo, 1993; Meneguetti et al., 2002). No presente trabalho, as doses de lodo de esgoto, sob diferentes formas, variaram de 13,8 a 33,2 t/ ha em base seca, sendo as quantidades função da quantidade de nitrogênio disponível para as plantas (Melo et al., 2002). Uma vez que a dose de lodo aplicada correspondeu ao dobro do requerimento de $\mathrm{N}$ para a cultura do milho, em razão de se considerar uma fração de mineralização de $50 \%$, pode-se pressupor a ocorrência de perdas deste elemento do solo, principalmente no início do ciclo vegetativo das culturas, intensificada pelo uso da irrigação, conforme verificado por Vieira e Cardoso (2003). De modo geral, a recomendação de aplicação de lodo de esgoto foi próxima da recomendada por Silva et al. (2002) que sugerem a aplicação de 21 t/ha de biossólido em base seca para se obter à produção máxima de milho em LATOSSOLO VERMELHO Distrófico. Por outro lado, Trannin et al. (2005), destacam que a dose de $10 \mathrm{t} / \mathrm{ha}$ de biossólido em base seca, suplementada com $\mathrm{K}_{2} \mathrm{O}$ e $30 \%$ da exigência em $\mathrm{P}_{2} \mathrm{O}_{5}$, proporciona produtividade de milho equivalente à obtida com adubação mineral completa.

\section{CONCLUSÃO}

1. A aplicação de lodo de esgoto tratado com cal contribui para o aumento da alcalinidade do solo,

2. Em geral, a adição de lodo de esgoto ao solo aumenta a concentração de nutrientes disponíveis para as plantas,

3. As variedades de milho crioulo e de feijão trepador cultivadas em consórcio, em solo de média fertilidade, não são influenciadas pela adubação química convencional e pela adição de lodo de esgoto.

\section{AGRADECIMENTOS}

Os autores agradecem a Fapemig e ao ICA/UFMG pelo suporte financeiro concedido ao projeto.

\section{BIBLIOGRAFIA}

ANDREOLI, C.V., FERNANDES, F., DOMASZAK, S.C. 1999. Reciclagem agrícola do lodo de esgoto: estudo preliminar para definição de critérios para uso agronômico e de parâmetros para normatização ambiental e sanitária. Curitiba, ed. SANEPAR, $82 \mathrm{p}$.

BARBOSA, G.M.C., TAVARES FILHO J., FONSECA, I. C. B. 2004. Condutividade hidráulica saturada e não saturada de Latossolo Vermelho eutroférrico tratado com lodo de esgoto. Revista Brasileira de Ciência de Solo 28 (2) 403-407.

BETTIOL, W., FERNANDES, S.A.P. 2004. Efeito do lodo de esgoto na comunidade microbiana e atributos químicos do solo. Jaguariúna, SP: Embrapa, 6 p. (Comunicado Técnico, 24).

EMBRAPA - Empresa Brasileira de Pesquisa Agropecuária/Centro Nacional de Pesquisa de Solos. 1997. Manual de métodos de análise de solo. Rio de Janeiro, $2^{\mathrm{a}}$. ed.

EMBRAPA/CNPS, 212 p. (Documento 01). HUE, N.V. 1995. Sewage sludge. In J. E. Rechcigl: Soil amendments and environmental quality. Boca Raton, FL: Lewis Publ., p. 193-239.

LOPES, J.C., RIBEIRO, L.G., ARAÚJO, M.G., BERALDO, M.R.B.S. 2005. Produção de alface com doses de lodo de esgoto. Horticultura Brasileira 23 (1) 143-147.

LOURENÇO, R.S., ANJOS, A.R.M., LIBARDI, P.L., MEDRADO, M.J.S. 1996. Efeito do lodo de esgoto na produtividade de milho e feijão no sistema de produção da bracatinga. Sanare 5 (5) 90-92.

MELO, W.J., MARQUES, M.O., MELO, V.P. 2002. O uso agrícola do biossólido e as propriedades do solo. In M. T. Tsutiya, J. B. Comparini, P. Alem Sobrinho, I. Hespanhol, P. C. T. Carvalho, A. J. Melfi, W. J. Melo, M. O. Marques: Biossólidos na agricultura. São Paulo, Companhia de Saneamento Básico do Estado de São Paulo, p. 289-363. 
MELO, W.J., MARQUES, M.O., SANTIAGO, G., CHELLI, R.A. 1994. Efeito de doses crescentes de lodo de esgoto sobre frações da matéria orgânica e CTC de um Latossolo cultivado com cana-de-açúcar. Revista Brasileira de Ciência de Solo 18 (3) 449-455.

MELO, V.P., BEUTLER, A.N., SOUZA, Z.M., CENTURION, J.F., MELO, W.J. 2004. Atributos físicos de latossolos adubados durante cinco anos com biossólido. Pesquisa Agropecuária Brasileira 39 (1) 67-72.

MENEGUETTI, G.A., GIRARDI, J.L., REGINATTO, J.C. 2002. Milho crioulo: tecnologia viável e sustentável. Agroecologia e Desenvolvimento Rural Sustentável 3 (1) 12-17.

NASCIMENTO, C. W. A., BARROS, D. A. S., MELO, E. E. C. OLIVEIRA, A. B. 2004. Alterações químicas em solos e crescimento de milho e feijoeiro após aplicação de lodo de esgoto. Revista Brasileira de Ciência de Solo 28 (2) 385-392.

OLIVEIRA, F.J., ARAÚJO, J.F. 1993. Avaliação agroeconômica de sistemas consorciado e solteiro com as culturas de caupi e milho. Pesquisa Agropecuária Brasileira 28 (2) 189 196.

OLIVEIRA, F.C., MATIAZZO, M.E., MARCIANO, C.R., ROSSETO, R. 2002. Efeitos de aplicações sucessivas de lodo de esgoto em Latossolo Amarelo distrófico cultivado com cana-de-açucar: carbono orgânico, condutividade elétrica, $\mathrm{pH}$ e CTC. Revista Brasileira de Ciência de Solo 26 (2) 505-519.

ROCHA, R.E.M., PIMENTEL M.S., ZAGO, V.C.P., RUMJANEK, N.G., POLLI H. 2003. Avaliação de biossólido de águas servidas domiciliares como adubo em couve. Pesquisa Agropecuária Brasileira 38 (12) 1435 1441.
SILVA, F. C., BOARETTO, A.E., BERTON, R.S., ZOTELLI, H.B., PEXE, C.A., MENDONCA, E. 1998. Cana-de-açúcar cultivada em solo adubado com lodo de esgoto: nutrientes, metais pesados e produtividade. Pesquisa Agropecuária Brasileira 33 (1) 1-8.

SILVA, J.E., RESCK, D.V. S., SHARMA, R.D. 2002. Alternativa agronômica para o biossólido produzido no Distrito Federal: I. efeito na produção de milho e na adição de metais pesados em latossolo no Cerrado. Revista Brasileira de Ciência de Solo 26 (2) 487-495.

SIMONETE, M.A., KIEHL, J.C., ANDRADE, C.A., TEIXEIRA, C.F.A. 2003. Efeito do lodo de esgoto em um Argissolo e no crescimento e nutrição de milho. Pesquisa Agropecuária Brasileira 38 (10) 1187-1195.

TEDESCO, M.J., GIANELLO, C., BISSANI, C.A., BOHNEN, H., VOLKWEISS, S.J. 1995. Análise de solo, plantas e outros materiais. Porto Alegre, $2^{\mathrm{a}}$ ed. Departamento de Solos/UFRGS, 174 p. (Boletim Técnico, 5).

TRANNIN, I.C.B., SIQUEIRA, J.O., MOREIRA, F.M.S. 2005. Avaliação agronômica de um biossólido industrial para a cultura do milho. Pesquisa Agropecuária Brasileira 40 (3) 261-269.

VIEIRA, R.F., CARDOSO, A.A. 2003. Variações nos teores de nitrogênio mineral em solo suplementado com lodo de esgoto. Pesquisa Agropecuária Brasileira 38 (7) 867-874. 